\title{
1 Day One Sustainability
}

2 Emissions reductions targets for the UK set out in the Climate Change Act for the peri-

3 od to 2050 will only be achieved with significant changes to the built environment,

4 which is currently estimated to account for $50 \%$ of the UK's carbon emissions.

5 The socio-technological nature of Civil Engineering means that this field is

6 uniquely placed to lead the UK through such adaptations. This paper discusses the im-

7 portance of interdisciplinary teaching to produce multi-faceted team approaches to sus-

8 tainable design solutions.

9 Methods for measuring success in education are often not fit for purpose, pro-

10 ducing good students but poor engineers. Real-world failures to apply sustainable de-

11 sign presents a serious, difficult to detect, and ultimately economically negative situa-

12 tion. Techniques to replace summative examinations are presented and discussed, with

13 the aim of enhancing core technical skills alongside those required for sustainable de-

14 sign.

15 Finally, the role of our future engineers in policy-making is discussed. In addi-

16 tion to carbon, the provision of water and food will heavily influence the work of civil

17 engineers in the coming decades. Leadership from civil engineers with the technical

18 knowledge and social awareness to tackle these issues will be required. This provides

19 both opportunities and challenges for engineering education in the UK. 
22 The built environment has a huge impact on the environmental, economic and social

23 well being of the UK. Research has consistently shown that the between 40 and $60 \%$ of

24 UK carbon emissions are associated with activities in the built environment (BIS 2010)

This paper discusses engineering sustainability from the perspective of teaching and research undertaken at the University of Bath Department of Architecture and Civil Engineering. A blended delivery of building physics, architecture and civil engineering is demonstrated as a key way in which academia can work with industry to provide graduates who have the skills required to meet global challenges beyond 2050.

The importance of instilling sustainability in all teaching from day one is presented and the role of industry, research, material use, and policy are all discussed. Challenges beyond embodied carbon reduction are introduced in the context of future teaching, and the role of assessment in all of these aspects is considered before conclusions are drawn.

\section{The University of Bath}

The joint Department of Architecture and Civil Engineering at the University of Bath was formed in 1965, and was led from 1976 by Professor Sir Ted Happold. Its successful approach to teaching engineers and architects together has gathered excellent rankings and student satisfaction in both disciplines.

The Department has an annual intake of approximately 200 undergraduate, 60 post-graduate taught and 20 post-graduate research students. The five undergraduate degree programs (BSc (Hons) Architecture; Master of Architecture; BEng Civil Engi- 
neering; MEng Civil Engineering; MEng Civil and Architectural Engineering) all offer placement opportunities.

Interdisciplinary research within the Department is currently focused in three main research groups, the output of each feeding directly into the relevant taught units:

(1) The BRE Centre for Innovative Construction Materials (BRE CICM) has 20 research active staff working in innovative and sustainable construction materials and technologies.

(2) The Centre for Advanced Studies in Architecture (CASA) supports collaborative research amongst architectural history, contemporary design, archaeology, conservation, and emerging digital technologies.

(3) The Energy and the Design of Environments (EDEn) group research lies primarily in the field of sustainable building design and building physics.

\section{Drivers}

The Climate Change Act (DECC 2008) sets out binding and ambitious targets for embodied $\mathrm{CO}_{2}$ emissions reductions (Figure 1). Meeting these targets will require concerted action from many disciplines, with the construction industry being one of the largest potential contributors to future success (Morrell 2010). Given that there are fewer than forty years until the target for an $80 \%$ reduction in carbon emissions must be met, providing graduates with the leadership and technical skills required to meet this challenge is essential.

\section{Day one}

Giving students both an understanding of the challenges the built environment faces, and tools to measure their impact upon it, is a critical stage in generating a mindset of 
sustainability. It is crucial that this is encouraged immediately, and new students on all degree programmes are introduced to sustainability on day one of their induction through the 'Carbon Counter' pocketbook (Lynas 2007).

Since we measure what we care about, and that we adjust our behaviour based on the metrics we are measured against (Ariely 2010), the 'carbon counter' is an appropriate first step. The University of Bath also publishes the Inventory of Carbon and Energy (Hammond and Jones 2011), a gold standard in measuring carbon, that is used throughout studio project work.

Providing students with a means by which carbon can be measured, however approximately, enables them to immediately optimise their approach to sustainability and has the potential to impact the way they undertake their personal and professional lives.

\section{Year 1}

After induction, the first year of education is crucial. 'Teaching' sustainability in the last semester of final year would be of no practical use, as students would not have had three-years worth of practical experience of making mistakes before they graduate.

Such a late introduction could also give the impression 1) that sustainability is not important or 2) that it can be bolted on to a project at the end; neither outcome is particularly helpful in conveying the importance of the subject.

Taught units with assessment directly relevant to sustainability in the undergraduate engineering programs within the Department are summarised in Figure 2, with the unit weighting given to first year clearly evident. Note that credit ratings are under the European Credit Transfer and Accumulation System (ECTS), rather than the Credit Accumulation and Transfer Scheme (CATS). 
93 Professor Doug King (visiting Professor at the University of Bath), in a report to the

94 Royal Academy of Engineering (King 2010), suggests that in order to properly address sustainability in the built environment, professionals with a fundamental understanding

96 of building engineering physics are needed to limit energy use while achieving desired

97 levels of environmental performance.

98 However, building engineering physics is not taught widely within undergradu-

99 ate degrees in the UK and there are just three MEng degree courses in the UK that are

100 accredited by the Chartered Institute of Building Services Engineers (CIBSE 2013)

101 which meet the Engineering Council requirements for Chartered Status. Additionally,

102 the Joint Board of Moderators (which combines the Institution of Civil Engineers, the

103 Institution of Structural Engineers, the Chartered Institution of Highways and Transpor-

104 tation and the Institute of Highway Engineers to accredit degree programs) requires stu-

105 dents of structural engineering to have only an awareness of building physics (JBM 106 2013)

107 Within the Department of Architecture and Civil Engineering, the taught unit

108 'Built Environment 1', undertaken in the first semester of first year, is dedicated to en-

109 ergy use in buildings, focusing on a fundamental understanding of energy flows and

110 building physics. This is critically important and is therefore undertaken as soon as pos111 sible.

112 The unit allows students to undertake basic physics calculations to inform deci-

113 sions about building orientation, envelope materiality and construction to achieve a de-

114 sirable internal environment. This process requires a degree of iteration and demonstra115 tion of how design changes influence the internal environment, and subsequent energy 
116 use. To supplement this, the students' design repertoire is enhanced through a range of

117 case studies focussing on both best practice and common mistakes.

\section{Assessment and adaptations for sustainability}

119 Within the broader context of a unit focusing on the fundamentals of structural design, coursework is used to investigate how design can influence environmental performance.

121 Every first year student analyses a building on the University of Bath campus by con-

122 sidering the architecture (does the intent work, how is the space used by inhabitants,

123 what is the circulation like); the structure (system used, materials, potential for recy-

124 cling, evidence of sustainable design); and the building environmental performance

125 (lighting, ventilation, acoustics, thermal comfort). Students must sketch cross-sections

126 and an internal view showing what the building is like to use. They are encouraged to

127 touch radiators, look for mould, comment on the air temperature, and to talk to the

128 building users.

129 Suddenly structural design is much more than strength and stiffness. The

130 coursework also requires an assessment of the building against modern sustainability

131 criteria. Aside from the newer buildings on the University of Bath campus, most per-

132 form badly (much of the campus was built in the 1960s). Finally, suggestions are made

133 as to how the building could be adapted to make it more sustainable and all of this in-

134 formation is presented on a single A3 sheet. Peer review of each student's work in the

135 form of a 'critique' allows the students to learn from each other.

136 Peer review forms an important part of first year work. This method of assess-

137 ment helps the students to better understand the importance of good communication in

138 engineering. A Water Tower design project takes up this concept. Working in groups,

139 the students must design a water tower within pre-defined material use constraints. The

140 design packs are then distributed so that each design group builds the structure designed 
141 by a different group. The importance of clear communication is then immediately ap-

142 parent, and each constructing group is able to provide useful feedback to the original

143 design group as they have all undertaken both sides of the process.

\section{Material choices}

145 Measuring carbon can drive the ways in which products are specified and used in con-

146 struction. However, considering operational efficiency but not embodied energy could

147 result in solutions that perform well in their lifespan, but need replacing often and add

148 significantly to total embodied energy and emissions (Sturgis and Roberts 2010).

149 As the proportion of whole life energy taken by operational energy in the built

150 environment falls, so the importance of limiting embodied energy rises. Sturgis and

151 Roberts (2010) also conclude that as much as $60 \%$ of whole life carbon could be ac-

152 counted for in embodied energy, and some analyses suggest that by 2050 improved en-

153 ergy efficiency could see $90 \%$ of whole life emissions arising from embodied energy

154 (Figure 3).

155 Material choices, therefore, require consideration of much more than just me-

156 chanical properties. Resource depletion and scarcity, carbon, and energy use must also

157 be a part of materials education.

158 Providing a broad knowledge base of innovative material choices is crucial in

159 this respect. In first year, two-page papers are used as a tool to achieve this. Students

160 must choose a construction material that is not steel, concrete, timber or masonry, and

161 consider current and future uses, carbon credentials and general sustainability issues.

162 They must also, crucially, discuss any opportunities the material presents for carbon re-

163 ductions. Examples of materials chosen range from rammed earth to cardboard, and

164 from glass to strawbales. 
166 knowledge sharing and peer review that gives the entire cohort a feel for the possibili-

167 ties of non-traditional construction materials.

\section{Summary}

169 First year education provides students with a basic vocabulary in structural design, ar-

170 chitecture and building engineering physics. This provides the basis for subsequent pro-

171 jects and discussions, makes them aware of the impingements upon the body that can be

172 caused by poor building physics, and introduces them to the principal design variables

173 of the built environment.

\section{Later years}

175 As students progress, the principles that they learnt in first year are reinforced by direct application to project work and supplementary taught units. In Years 2 and 3, building engineering physics is developed within two further units.

Building Environment 2 (Year 2) builds on the passive design methods introduced in in Year 1 by considering the active control of building environments. Heating,

180 ventilation, day lighting, fire suppression, and acoustic systems are all considered. Students are then able to qualitatively and quantitatively assess environmental control systems.

184 two units. Specific topics include low and zero carbon heating system technologies, as-

185 sessment of occupant thermal comfort, heating degree-days to estimate energy use and the introduction of Passivhaus design concepts. Alongside these the Department also runs an annual week-long bespoke Passivhaus course for its students, which prepares them for the official Passivhaus examination, should they wish to register for it. The ap- 
189 plied nature of Building Environment 3 is specifically intended as preparation for the

190 subsequent design projects and eventual graduate work.

191 In Year 3 a joint engineer-architect project focuses on reducing material use and

192 constructability, and in Year 4 the 'Basil Spence Project' is fundamentally all about cre-

193 ating an holistic design which encompasses architecture, structure and building physics

194 innovation in order to achieve an inspirational low-energy use building.

\section{Materials}

196 Embedding materials into all aspects of teaching allows students to link their material

197 choices to scarcity, carbon, future proofing and reuse. This feeds directly into design

198 projects where carbon counting is used as one tool in the assessment of design deci-

199 sions, helping to demonstrate the importance of material choices for sustainable design.

200 This is quite different to more conventional materials teaching that may consider only

201 chemical composition, structural properties and financial cost.

202 Beyond undergraduate programs, post-graduate taught courses must also provide materials teaching. Within the MSc in Civil Engineering: Innovative Structural Materials, topics including advanced timber engineering, fibre reinforced polymers, sustainable concrete technology and glass engineering are introduced.

Both undergraduate and post-graduate courses within the Department are linked to our research activities. This is important for both academics and students and is reinforced at an annual departmental research seminar in which all students are invited to listen to brief research summaries from every academic. This seminar ensures students

210 are introduced to what we are doing in all areas of sustainability.

\section{Research}

212 Research is hugely important for developing taught units and research outcomes are fed 
213 directly into taught units. Developing the use of radical, low-carbon building materials

214 and reinforcement technologies to aid decarbonisation of the built environment is the

215 key goal of the BRE Centre for Innovative Construction Materials. Material innovations

216 arising from the centre are strongly embedded in teaching and project work throughout

217 engineering and architectural degree courses.

218 Increasingly, taught units use computation for design and analysis. The Centre

219 for Advanced Studies in Architecture (CASA) supports this through its research in par-

220 ametric design and multiple-objective layout optimisation for complex structures. The

221 centre works regularly with industry to apply their knowledge to real problems

222 (Shepherd and Williams 2010), allowing students to see the impact that research can

223 have on their industrial practice.

224 Research in building physics by the Energy and the Design of the Environment 225 group focuses on extremely low-energy buildings that meet the requirement for an $80 \%$

226 cut in emissions by 2050 and the refurbishment of existing structures - both areas that

227 will be crucially important throughout our students' careers. Alongside this research is

228 undertaken into the future of cities and the way interconnections between people and in-

229 frastructure will be important for transforming the efficiency of energy use, creation and 230 distribution within urban areas.

\section{Industry}

232 Given that higher education is the primary route to entry into the engineering profes-

233 sion, strong links must be maintained between industry and academia. A tripartite ap-

234 proach utilising 1) visiting staff, 2) an industrial liaison panel, and 3) our alumni, has

235 been successful within the Department.

236 The Department employs some 150 visiting tutors each year, all of whom are 237 chosen in part for their sustainability credentials. As a result, students are exposed to 
238 leaders in sustainability from both an academic and industrial perspective. This is evi239 denced by eleven of our visiting Professors and alumni being included in Building De-

240 sign Magazine's Top 50 Green Leaders (Gilbert 2012).

241 An industrial liaison panel made up of forty members from across the UK pro-

242 vides input on all aspects of teaching and research programs undertaken within the De-

243 partment. This input is crucial and must be timely - changes made to a first year degree course in 2013 will only be seen in the graduates of 2016/17.

From these links with industry our students are quickly encouraged to form a sustainability mindset in their first year of study. They begin to understand that, at least initially, they will not be judged by the mistakes that they make, and that making mistakes is crucial for learning and is far better than not trying at all. Learning from these mistakes and disseminating best practice is a key tool for sustainability in the built environment.

The success of our teaching program is reflected in the achievements of our graduates. Graduate Kai Qu (2010) was named the Institution of Structural Engineers Young Engineer of the year in 2013 (IStructE 2013), several of our alumni sit on the

254 Council of the Institution of Structural Engineers, and 2008 graduate Oliver Neve won the Institution of Civil Engineers Graduate and Student Papers Competition in 2012.

Other alumni successes include the IStructE Supreme Award for Structural Engineering in 2011 for the Olympic Velodrome, the award for sports or leisure structures, the David Alsop Award for sustainability, and the Heritage Award for Building or Infrastructure Projects (IStructE 2011).

\section{Beyond Carbon}

261 Carbon, water and food form the cornerstones of our sustainability agenda in both research and teaching. Each of these aspects is covered in our current teaching portfolio, 
with relative importance changing as new funding and research centres are launched.

265 Averaged over a global population, there is sufficient fresh water on the globe for everyone's future needs (UN 2013), yet such a simplification overlooks the problem of re-

267 gional water scarcity that affect billions of people (UN 2012). Changes in water policy, and management in food production, will be required to meet growing demands for water resources.

Civil Engineers are well versed in the demands of managing and moving water, giving them the ability to shape global access to water. The technology to do this is available; getting it into practice will be a question of policy making and political will. Investment in a water quality laboratory is the first step in a new program of research in this field. A dedicated, newly built laboratory within the Department is due to launch in 2014, with this infrastructure investment being matched by funding for new research staff positions. A second collaborative project worth $£ 2.5 \mathrm{M}$ between the Department of Chemical Engineering and Wessex Water Ltd to set up a 'Water Innovation and Research Centre' will be launched in 2014. The centre will provide a unique environment to conduct water technology and resource management research, and civil en-

280 gineering academics will be involved. This research, along with inter-departmental collaborations will lead to the changes to teaching that are required to meet our sustainability challenges to 2050 .

\section{Food}

284 Global populations rising towards 9 billion by 2050 (Chamie 2004), coupled with changing and increasingly rich diets, is driving up demand for food. Some estimates

286 suggest that the increase in demand could exceed $50 \%$ by 2030 (Zoellick 2008). 
diet - global food production could already provide upwards of 2700 calories per person per day (FAO 2002). Yet this is not the case as food is wasted, people cannot afford it, or it is badly distributed.

Simply ensuring that global farmers reach their production potential, which would require no new technologies, could provide a 50\% increase in yields (Foley et al.

293 2011), making the problem of food provision primarily one of management and not science.

Civil engineers have the capacity to lead in this area, where policy, coupled with political and social stability, is key. The management of land has analogies with the management of construction projects, where resources are balanced with cost over time to ensure the desired end result is achieved. These skills are taught across the curriculum in 'Construction Management' and are transferrable into wider fields, such as food and land management.

Stronger regulation and government policy is required in many countries to provide a global food network with robustness against economic events and climate change. Increasing food prices has been closely linked with civil unrest after the food crises of 2008 and 2010 (Bellemare 2012).

Although the period 2050-2080 may not be as productive as 1950-1980 (Fraser 2013), this does not necessarily imply that food will be more scarce than it is today. Rather, a change in the way that food is dealt with will be required. Having the solutions means that policy makers need support to make the decisions that are necessary.

310 Engineers will be in food. This is fundamentally a Civil Engineering problem, as seen in 311 work by Norton and Lane (2012) and Shrivastava (2003). Its solution will come from 
312 land management and international government policy, informed by the research-led

313 teaching in food, water and waste management of our future Civil Engineers.

\section{Policy}

315 Both food and water, the big global issues after carbon, require strong leadership and management to implement many of the technological revolutions that have been availa-

317 ble for some decades.

Within hydraulics, our teaching already includes water management policy as a core topic. Understanding global differences in water policy is crucial if the challenges outlined above are to be met.

However, weak political structures can mean that decisions are never made, or ultimately have little to do with money, and more to do with weak leadership in policy making that means decisions are not made (because no-one has the support or knowledge to make the decision).

These challenges are demonstrated in Tanzania, where despite water resources of $2300 \mathrm{~m}^{3}$ per capita (Frenken 2005) widespread water scarcity exists due to low water storage capacity, variations in rainfall distribution and intensity, and institutional weaknesses in water management (MKUKUTA 2007).

This makes the provision of water and construction management education crucial. Students are shown how important it is to get involved in policy-making decisions; and this means that they must become leaders.

\section{Assessment}

334 Assessing engineering degrees can lead to contradictions in practice. Students are

335 judged by exam results, but examinations are not what an engineer does. Industrial 
336 feedback suggests that on occasion first class students show less skill in industrial set-

337 tings than some with a third class degree. Such a situation simply shows that degree

338 classifications can measure the wrong thing.

339 Assessment by closed book examination is one means by which this situation

340 can arise as such exams often take the form of a memory test rather than assessing fun-

341 damental understanding. This is pertinent in structural analysis, where a full understand-

342 ing of the principles adds coherence to subsequent calculations (May and Johnson 2008)

343 and avoids surface learning effects.

344 Examinations themselves have also changed, with questions now designed to

345 test an ability to think in a qualitative way being desirable. More traditional mathemati-

346 cal assessment can then be undertaken as coursework, which better represents the reality

347 of engineering practice.

348 The future may see examinations becoming the background, rather than front-

349 line, assessment. This is illustrated in Figure 4 where a proposed unit assessment route

350 is shown. Assessment by short individual or group projects and workshops (1 hour to 1

351 day in length) inserted throughout the semester would allow students to demonstrate

352 their working and practical knowledge of a subject. Assessment of up to $80 \%$ of the unit

353 marks in this way would then be supported by a final examination focusing on their

354 ability to think around key topics. The key to this approach is that the examination

355 would have to be passed to progress, but the weighting given to it would be appropriate-

356 ly low.

357 It is envisaged that such an approach would generate engagement (through

358 workshop sessions) and a more philosophical outlook of graduates. Under this model of

359 assessment, a student awarded a first class degree would (it is hoped) graduate as a first

360 class engineer capable of an holistic approach to sustainable design. 
362 The extra-curricular endeavours of students must be supported at all stages. Providing opportunities and financial support to explore ideas is key to this. Since 1998 The Happold Trust has supported a travel scholarship for one or two final year students. Modest financial support (£1000) has achieved great things and provided real benefits to our

366 graduating students. Recent projects include:

- 2013 - When the Levee Breaks: Dealing with the aftermath of storms in the partment. Students who undertake these opportunities tend to learn more than they provide to the people they visit and this is a key reason why support is provided.

\section{Conclusions}

379 This paper has shown how a blended delivery of engineering, architecture, building

380 physics and the freedom to experiment can provide a basis for sustainable design in the

381 built environment. Introducing a way of thinking in first year that is then reinforced in

382 subsequent teaching and project work has been key to the success of this approach at 383 Bath. 

engineering sustainability. Our annual reviews of teaching mean that the course content is able to change quickly, if needed. This paper does not presume to suggest that we have done everything right, but aims to demonstrate the success we have achieved with the methods we have used. It should act as a discussion point for engineering education. A current emphasis on building environmental physics is set to increase in the

390 future and this should be common across all civil engineering degrees. More universities need to get building physicists involved in their teaching and research, with the possibility for future MEng level degree programs in Building Engineering Physics as a third strand to the 'classic' architecture and civil engineering programs. this means taught design units must include these issues. This should be matched with appropriate examination techniques that assess students' ability to think rather than to do sums. role of our industrial liaison panel has been important in developing the degree program that is run today. to achieving change in the built environment and will be driven forwards through education.

Finally, all of these aspects have been achieved whilst retaining $100 \%$ positive student feedback across all graduate program areas (HEFCE 2012). Challenging and motivating students with high quality teaching and assessment methods is key to con407 tinuing this. 


\section{References}

409

410

411

412

413

Ariely, D. 2010. "You Are What You Measure." Review of. Harvard Business Review $88(6): 38$.

Bellemare, M F. 2012. "Rising Food Prices, Food Price Volatility, and Social Unrest." In American Political Science Association 2012 Annual Meeting. Duke University - Sanford School of Public Policy.

\section{BIS. 2010. "ESTIMATING THE AMOUNT OF CO2 EMISSIONS THAT THE} CONSTRUCTION INDUSTRY CAN INFLUENCE: Supporting material for the Low Carbon Construction IGT Report." In. London: BIS (Department for Business Innovation and Skills).

Chamie, J. 2004. "World Population to 2300." In. New York: United Nations.

CIBSE. 2013. "Accreditation of Programmes." CIBSE, Accessed 20 Jun. http://www.cibse.org/content/Accreditation of Programmes.xls.

DECC. 2008. "Climate Change Act 2008." In. London: The Stationery Office.

\section{FAO. 2002. "REDUCING POVERTY AND HUNGER: THE CRITICAL ROLE OF} FINANCING FOR FOOD, AGRICULTURE AND RURAL DEVELOPMENT." In International Conference on Financing for Development Monterrey, Mexico: United Nations Food and Agricultural Organisation.

Foley, JA, N Ramankutty, KA Brauman, ES Cassidy, JS Gerber, M Johnston, ND Mueller, et al. 2011. "Solutions for a cultivated planet." Review of. Nature 478 (7369):337-42.

Fraser, E. 2013. "Feeding Nine Billion." University of Guelph, Accessed 22 July. https://feedingninebillion.com/.

Frenken, K. 2005. "Irrigtion in Africa in Figures AQUATSTAT Survey." In. Rome: Food and Agricultural Organisation of the United Nations.

Gilbert, D. 2012. "BD's top 50 green leaders." In Building Design. London: Building Design.

Hammond, G.P, and C.I Jones. 2011. "Embodied energy and carbon in construction materials." Review of. Proceedings of the Institution of Civil Engineers: Energy In Press.

HEFCE. "The National Student Survey 2012." The Higher Education Funding Council For England. 
IStructE. 2013. "Structural Awards 2012." IStructE, Accessed 22 July. http://www.istructe.org/structuralawards/2013/previous-winners.

_. 2013. "Young Structural Engineer of the Year Award 2013." IStructE, Accessed 22 July. http://www.istructe.org/events-awards/people-and-papersawards-luncheon-2013/young-structural-engineer-of-the-year-2013.

Lane, T. 2011. "Our dark materials." Building, Accessed 01/01.

http://www.building.co.uk/comment/our-dark-materials/3099435.article.

Lynas, M. 2007. Carbon Counter. London: Collins.

May, I M, and D Johnson. 2008. "The teaching of structural analysis: A report to The Ove Arup Foundation." In. London: Joint Board of Moderators.

MKUKUTA. 2007. "Poverty and Human Development Report." In. Dar es salaam: Research and Analysis Working Group, United Republic of Tanzania.

Morrell, P. 2010. "Low Carbon Construction. Innovation \& Growth Team." In. London: Department for Business, Innovation and Skills.

Norton, M, and A Lane. 2012. "'New Water Architecture': an integrated water management model." Review of. Proceedings of the ICE - Management, Procurement and Law 165 (3):159 -71.

Shepherd, P, and C. J. K. Williams. 2010. "British Museum Great Court." In The New Mathematics of Architecture, edited by J Burry and M Burry, 122-5. New York: Thames \& Hudson.

Shrivastava, G. 2003. "Water resources and food security: a Caribbean case study." Review of. Proceedings of the ICE - Water and Maritime Engineering 156 (4):351-3.

Sturgis, S, and G Roberts. 2010. "Redefining Zero: Carbon profiling as a solution to whole life carbon emission measurement in buildings." In. London: RICS. UN. 2012. "Managing Water under Uncertainty and Risk. THE UNITED NATIONS WORLD WATER DEVELOPMENT REPORT 4." In. Paris: United Nations Educational, Scientific and Cultural Organisation. 
473

474

475

476

477

478 United Nations, Accessed 20 Jun.

Zoellick, R B. 2008. "World development report 2008 - Agriculture for Development." In. Washington, DC: The World Bank. 


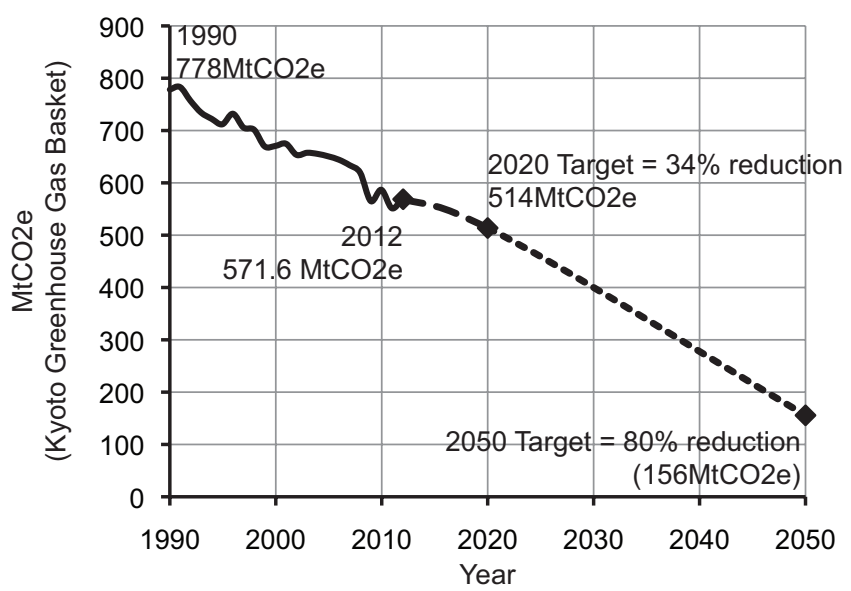

480 Figure 1. Targets for emissions reductions in the UK (DECC 2008)

481

482

483

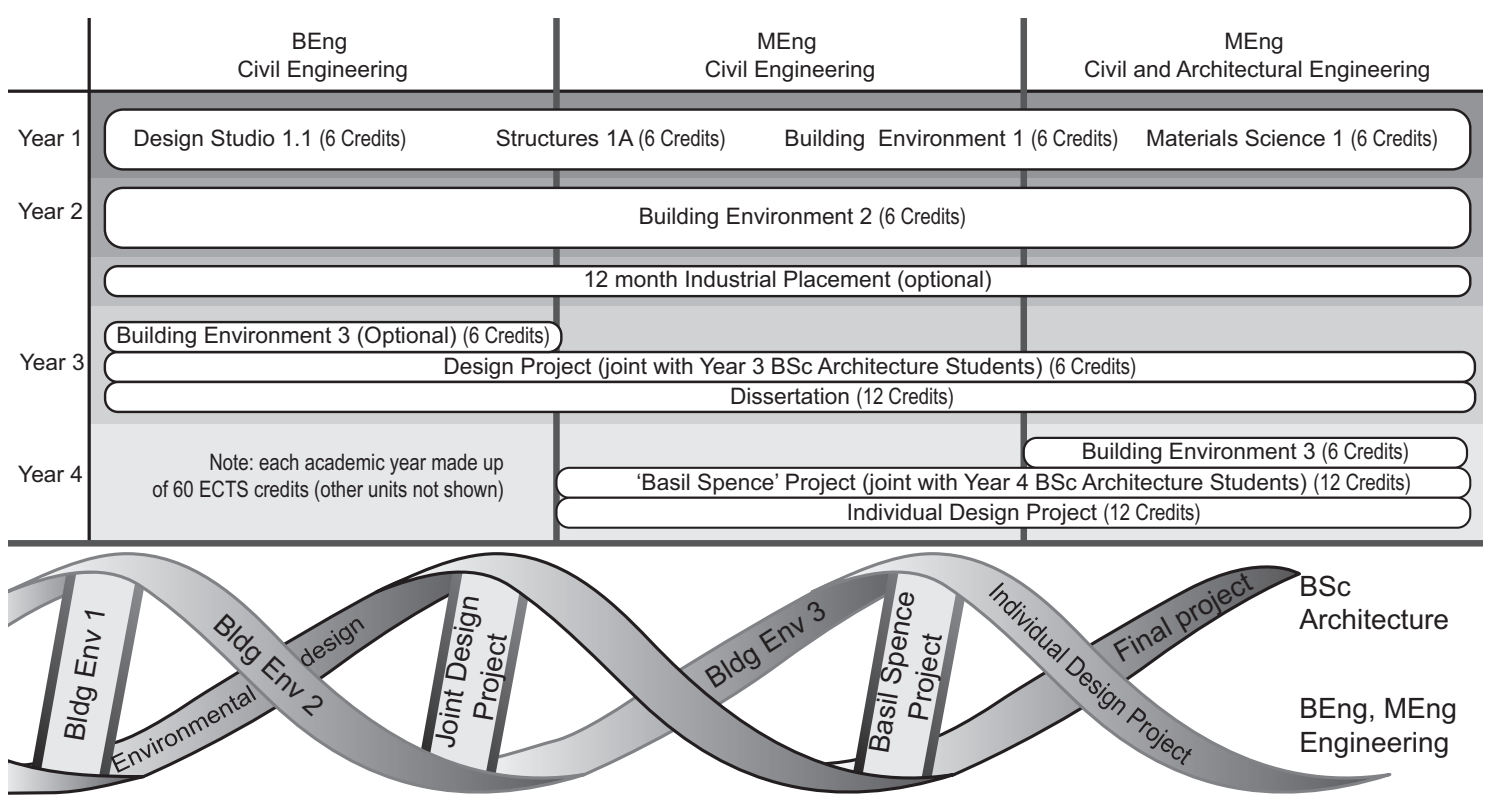

484 Figure 2. Degree program overview, relevant units only (top) and links between Archi-

485 tecture and Engineering units (bottom, after King (2010))

486

487 

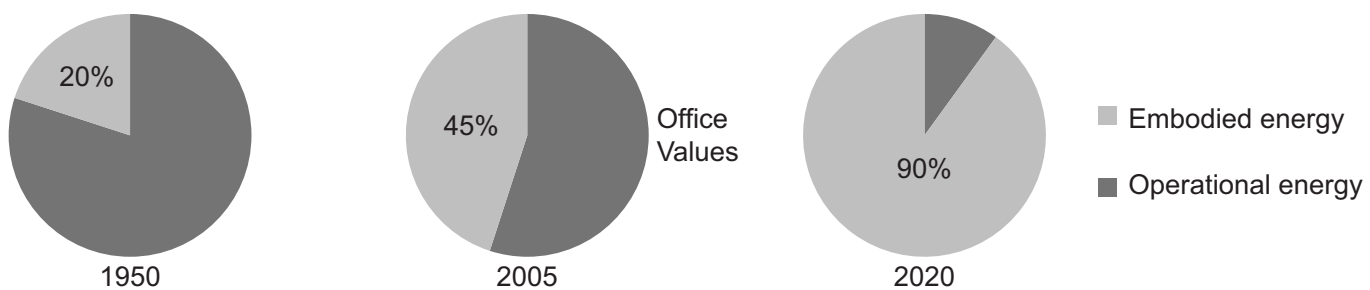

490 Figure 3. Embodied energy versus Operational energy use from 1950-2050 (after Lane 491 (2007) and Sturgis and Roberts (2010))

492

493

Typical current unit

\begin{tabular}{|c|c|}
\hline Lectures & $30-40$ hours \\
\hline Coursework & $50 \%$ \\
\hline \multicolumn{2}{|c|}{$\downarrow$} \\
\hline Examination & $50 \%$ \\
\hline
\end{tabular}

494

495

Figure 4. A new model for assessment

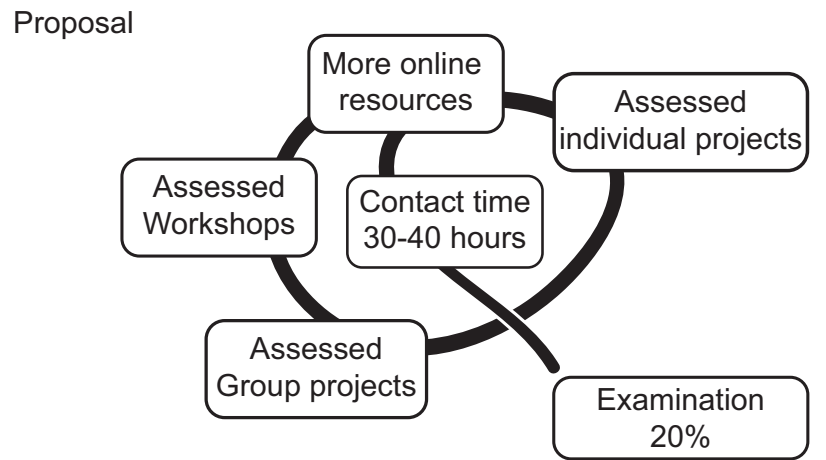

